\title{
Silver nanoparticles with different concentrations and particle sizes affect the functional traits of wheat
}

\author{
S. WANG ${ }^{1}$, B. D. WU ${ }^{1}$, M. WEI ${ }^{1}$, J. W. ZHOU ${ }^{1,2}$, K. JIANG $^{1}$, and C.Y. WANG ${ }^{1,3 *}$ \\ Institute of Environment and Ecology, Jiangsu University, Zhenjiang 212013, P.R. China ${ }^{1}$ \\ School of the Environment, Nanjing University, Nanjing 210023, P.R. China ${ }^{2}$ \\ State Key Laboratory of Pollution Control and Resource Reuse, Tongji University, Shanghai, 200092, P.R. \\ China $^{3}$
}

\begin{abstract}
The response of functional traits of plants to external environment can influence their competitive ability because these functional traits are required for the acquisition of resources. The overuse of silver nanoparticles (AgNPs) has gained attention due to their environmental toxicity. This study aimed to examine the effects of AgNPs with different concentrations and particle sizes on functional traits of wheat. It was observed that AgNPs significantly reduced the plant height and so decrease its competitive ability. Ag ions decreased leaf chlorophyll and nitrogen content and specific leaf area more than AgNPs, but the opposite was true for leaf length, single leaf fresh mass, and shoot fresh mass. Hence, the toxicity of AgNPs may be higher than that of Ag ions in some cases. In this study, leaf chlorophyll and nitrogen content decreased with increasing concentration of AgNPs (with size $30 \mathrm{~nm}$ ). The AgNPs with smaller particle size exerted higher toxicity on leaf chlorophyll and $\mathrm{N}$ content than those with larger particle size at the same concentration. However, AgNPs with larger particle size reduced more aboveground fresh mass than those with smaller particle size at the same concentration.
\end{abstract}

Additional key words: Ag ions, chlorophyll, competitive ability, nitrogen, resource acquisition, specific leaf area, toxicity.

\section{Introduction}

Plant species needs their functional traits to respond to the variations in environmental conditions (Pietsch et al. 2014, Wang et al. 2017a,b, Jiang et al. 2019). In particular, the response of leaf functional traits to the external environment can help to expand their habitat niches because leaves play a vital role in the acquisition of resources, such as sunlight (Liu et al. 2010a, Meng et al. 2014, Jiang et al. 2019). Thus, the response of leaf functional traits is regarded as an important factor for good growth and development (Vile et al. 2005, Wang et al. 2017a, b, 2018a-d, Jiang et al. 2019). As one of the most important functional traits, specific leaf area (SLA, defined as the leaf area per unit leaf biomass), determines the resource acquisition strategies, such as trade-offs between storage resource and rapid growth (Kardel et al. 2010, Scheepens et al. 2010, Pietsch et al. 2014). In general, high values of SLAs are closely related to greater acquisition and utilization efficiency for available resources and less investment in leaf structures. Further, low values of SLAs have been found to be strongly related to greater amount of investment in leaf structures and relatively low growth rates (Kardel et al. 2010, Scheepens et al. 2010, Pietsch et al. 2014). In addition, leaf size, leaf shape index, and leaf chlorophyll and nitrogen content are essential leaf functional traits, which are highly correlated to plant resource-utilization strategy (Wang and Zhang 2012, Wang et al. 2016, 2017a,b). Moreover, plant height also contributes towards the competitive ability for sunlight acquisition (Gross et al. 2007, Thomson et al. 2011).

Presently, one of the important environmental issues is the extensive use of nanomaterials. Their excellent physicochemical properties and the correspondingly environmental activities are attributed to the small particle size, which usually ranges from 1 to $100 \mathrm{~nm}$ (Nowack and Bucheli 2007, Pulit-Prociak et al. 2015). Among the various nanoparticles, silver nanoparticles (AgNPs)

Submitted 1 February 2019, last revision 10 August 2019, accepted 20 September 2019.

Abbreviations: AgNPs - silver nanoparticles; Chl - chlorophyll; SLA - specific leaf area.

Acknowledgements: This study was supported by the National Key Research \& Development Program of China (2016YFC0502002), the Open Science Research Fund of State Key Laboratory of Pollution Control and Resource Reuse (Tongji University), China (PCRRF17015), the Priority Academic Program Development of Jiangsu Higher Education Institutions (PAPD), the Student Scientific Research Project, Jiangsu University, and Jiangsu Collaborative Innovation Center of Technology and Material of Water Treatment. We are very grateful to the anonymous reviewer for the insightful and constructive comments that greatly improved this manuscript.

* Corresponding author; fax: (+86) 511 88790955, e-mail: liuyuexue623@163.com 
are extensively used due to their unique antimicrobial performance and other physiochemical properties (PulitProciak et al. 2015, Batista et al. 2017). Global AgNPs production is estimated over 400 tons annually, and $30 \%$ of its production is mainly used in medical applications (Pourzahedi and Eckelman 2014, Batista et al. 2017). The widespread and increasing production and use of AgNPs generate the concern of their release into environment (such as farmland, rivers, lakes, etc.) due to their toxicity to living organisms (Batista et al. 2017, Rahmatpour et al. 2017, Schlich et al. 2017). In higher plants, they can cause membrane disruption (Farkas et al. 2011, Wang et al. 2017c), oxidative stress (through Fenton reactions) (Huang et al. 2010, Li et al. 20017), chromosomal aberrations, DNA mutations, DNA repair inhibition, DNA methylation (Ng et al. 2010), cell death (Wan et al. 2012), reduction of the growth and development (Jasim et al. 2017), seed germination and seedling growth (Yin et al. 2012, Vannini et al. 2014, Zuverza-Mena et al. 2016, Wang et al. 2018a), plant transpiration (Gubbins et al. 2011, Kim et al. 2011), and enzyme activities (McGee et al. 2017, Rahmatpour et al. 2017).

The objective of this study was to gain insights into the response of several traits (plant height, leaf size, leaf shape index, SLA, leaf chlorophyll content, and leaf N content) of wheat to AgNPs with different concentrations and particle sizes.

\section{Materials and methods}

Experimental design: Wheat (Triticum aestivum L.) was cultivated in pots (4 seedlings per pot) with humus ( $\mathrm{pH} \sim 6.5$, organic matter $\geq 40 \%$, electrical conductivity $\leq 3 \mathrm{mS}$ $\mathrm{cm}^{-1}$; Hongyang Agricultural Science \& Technology Co., Huai'an, China). The potted seedlings were then exposed to AgNPs obtained from Shanghai ST-Nano Science \& Technology Co., Shanghai, China (purity $\geq 99.8 \%$ ) with concentrations: L- $100 \mathrm{mg} \mathrm{kg}$ (soil) $)^{-1}, \mathrm{M}-200 \mathrm{mg} \mathrm{kg}$ (soil) $^{-1}$, and $\mathrm{H}-400 \mathrm{mg} \mathrm{kg}(\mathrm{soil})^{-1}$ and particle sizes 30, 50, and $70 \mathrm{~nm}$. Distilled water was used as a control (CK). AgNPs suspensions were continuously stirred for complete distribution to avoid particle polymerization using an ultrasonic generator (KQ-250DE, Kunshan Ultrasonic Instruments, Suzhou, China). The operating parameters were: $40 \mathrm{kHz}$ with a maximum power output of $100 \mathrm{~W}$ at room temperature (Cvjetko et al. 2017, Rahmatpour et al. 2017, Wang et al. 2018a). In addition, the potted seedlings were also treated with $\mathrm{AgNO}_{3}$ solution (purity $\geq 99.8 \%$, Sinopharm Chemical Reagent Co., Shanghai, China) with concentrations 100,200 , and $400 \mathrm{mg} \mathrm{kg}$ (soil) ${ }^{-1}$. Each experiment was performed in triplicates (i.e. three pots). The experiments were conducted in a glasshouse at Jiangsu University in Zhenjiang, China $\left(32.206{ }^{\circ} \mathrm{N}, 119.512^{\circ} \mathrm{E}\right)$ under natural sunlight from February to April, 2017. The site has a north subtropical monsoon humid climate, with an annual mean temperature of $\sim 16.1{ }^{\circ} \mathrm{C}$, annual mean precipitation of $\sim 1150.6 \mathrm{~mm}$, and mean duration of sunshine $\sim 1986.9 \mathrm{~h}$. The mean monthly values of the above parameters from February to April were $\sim 10.0^{\circ} \mathrm{C}$, $\sim 73.7 \mathrm{~mm}$, and $\sim 154.0 \mathrm{~h}$, respectively. The summaries of the site climate were obtained from local records (Hang and $\mathrm{Wu} 2017)$.

All wheat samples were collected at the end of the cultivation period. Five fully developed, mature, and undamaged leaves from each individual were randomly selected to evaluate their functional traits. All samples were stored in sealed bags and immediately transported back to the laboratory to determine the corresponding indices.

Determination of functional traits: Plant height was estimated by measuring the distance between the base of the stem and apical shoot or tallest leaf with a ruler (Wang et al. 2017a,d,e, 2018a-d, 2019, Jiang et al. 2019).

Leaf shape index was determined using the ratio of the leaf length to the corresponding leaf width (Jeong et al. 2011, Wang and Zhang 2012, Li et al. 2016). Leaf length (the maximum value along midrib) and leaf width (the maximum width perpendicular to midrib) were evaluated using a ruler.

Relative $\mathrm{N}$ content in the leaves were measured using a hand-held plant nutrient meter (TYS-3N, TOP Instrument Co., Hangzhou, China). The chlorophyll (Chl) content was determined in "SPAD units" based on absorbances at $650 \mathrm{~nm}$ and $940 \mathrm{~nm}$ (Jiang et al. 2019).

The shoot and single-leaf fresh and dry masses were estimated using an electronic balance with $0.001 \mathrm{~g}$ accuracy; dry mass after drying the samples in oven at $60{ }^{\circ} \mathrm{C}$ for $24 \mathrm{~h}$ when a constant mass was achieved (Wang et al. 2016). SLA was calculated as a ratio of the leaf area to corresponding leaf dry mass (Kardel et al. 2010).

Determination of $\mathbf{A g}$ content: $\mathrm{Ag}$ content in soil and plant was estimated with acid digestion methods $\left(\mathrm{HNO}_{3}-\right.$ $\mathrm{H}_{2} \mathrm{O}_{2}$-HF) using iCAP 6300 inductively-coupled plasma atomic emission spectrometer (ICPAES, Thermo Fisher Scientific, Waltham, MA, USA).

Statistical analysis: Differences in the values of functional traits of wheat among various treatments were evaluated by analysis of variance ( $A N O V A$ ) followed by StudentNewman-Keuls test for multiple comparisons, when required. Two-way $A N O V A$ was used to assess the effects of different concentration and particle size of AgNPs on the functional traits of wheat. Meanwhile, the partial etasquared $\left(\eta^{2}\right)$ values were determined to evaluate the effect of size of each factor for use in the two-way ANOVA. Correlation analysis was performed using Pearson product-moment correlation coefficient to evaluate the relationships between functional traits of wheat and Ag content in plant and soil and $P \leq 0.05$ was considered as statistically significant. All statistical analyses were performed using IBM SPSS statistics (version 22.0, IBM Corp., Armonk, NY, USA).

\section{Results}

ANOVA results showed that the concentration of AgNPs significantly affected leaf width, leaf $\mathrm{Chl}$ and $\mathrm{N}$ content, 
and shoot fresh mass of wheat $(P<0.05$; Table 1 Suppl.). The particle size of AgNPs and also $\mathrm{AgNO}_{3}$ significantly affected plant height, leaf width, aboveground dry mass, and plant Ag content. The interaction between the concentration and particle size significantly affected plant height, and leaf chlorophyll and $\mathrm{N}$ content as well as soil $\mathrm{Ag}$ content. Plant height of wheat was significantly reduced under all treatments, when compared to control. Similarly, leaf length was significantly decreased under moderate concentration of AgNPs with size $70 \mathrm{~nm}$ compared to control. Further, the leaf width was significantly decreased under low concentration of AgNPs with size $70 \mathrm{~nm}$ and moderate concentration of AgNPs with size 50 or $70 \mathrm{~nm}$ compared to control. Leaf Chl content was significantly reduced under low concentration of AgNPs with size $70 \mathrm{~nm}$, moderate concentration of AgNPs with size $50 \mathrm{~nm}$, and high concentration of AgNPs of all particle sizes compared to control $(P<0.05$; Table 1). Leaf $\mathrm{N}$ content was significantly reduced under all treatments (except under low and moderate concentrations of AgNPs with size of $30 \mathrm{~nm}$ ). Similarly, aboveground fresh mass was found to be significantly lower under low and moderate concentrations of AgNPs with size of $70 \mathrm{~nm}$ compared to control $(P<0.05$; Table 1$)$.

Table 1. Differences in the functional traits of wheat under AgNPs and $\mathrm{AgNO}_{3}$. Means $\pm \mathrm{SEs}, n=3$, different lowercase letters indicate significant differences $(P<0.05)$ determined with an analysis of variance among groups followed by the Student-Newman-Keuls test for multiple comparisons (ns - no significant difference). Abbreviations: CK - control; AgNP30L - low concentration of AgNPs with size of $30 \mathrm{~nm}$; AgNP30M - moderate concentration of AgNPs with size of $30 \mathrm{~nm}$; AgNP30H - high concentration of AgNPs with size of $30 \mathrm{~nm}$; AgNP50L - low concentration of AgNPs with size of $50 \mathrm{~nm}$; AgNP50M - moderate concentration of AgNPs with of $50 \mathrm{~nm}$; AgNP50H, high concentration of AgNPs with size of $50 \mathrm{~nm}$; AgNP70L - low concentration of AgNPs with size $70 \mathrm{~nm}$; AgNP70M moderate concentration of $\mathrm{AgNPs}$ with size of $70 \mathrm{~nm} ; \mathrm{AgNP} 70 \mathrm{H}$ - high concentration of AgNPs with size of $70 \mathrm{~nm} ; \mathrm{AgNO}_{3} \mathrm{~L}-\mathrm{low}$ concentration of $\mathrm{AgNO}_{3} ; \mathrm{AgNO}_{3} \mathrm{M}$ - moderate concentration of $\mathrm{AgNO}_{3} ; \mathrm{AgNO}_{3} \mathrm{H}$ - high concentration of $\mathrm{AgNO}$; $\mathrm{PH}$ - plant height; LL - leaf length; LW - leaf width; LSI - leaf shape index; LCC - leaf chlorophyll content; LNC - leaf N content; SLFM - single leaf fresh weight; SLDM - single leaf dry mass; SLA - specific leaf area; AFM - aboveground fresh mass; ADM - aboveground dry mass.

\begin{tabular}{|c|c|c|c|c|c|c|c|c|c|c|c|}
\hline Treatment & $\mathrm{PH}$ & LL & LW & LSI & LCC & LNC & SLFM & SLDM & SLA & AFM & $\mathrm{ADM}$ \\
\hline \multirow[t]{2}{*}{ CK } & $26.83 \pm$ & $22.89 \pm$ & $1.26 \pm$ & $18.16 \pm$ & $41.89 \pm$ & $3.51 \pm$ & $0.37 \pm$ & $0.09 \pm$ & $172.92 \pm$ & $14.60 \pm$ & $2.63 \pm$ \\
\hline & $0.62 \mathrm{a}$ & $0.53 \mathrm{ab}$ & $0.01 \mathrm{a}$ & $0.56 \mathrm{~ns}$ & $1.15 \mathrm{a}$ & $0.06 \mathrm{a}$ & $0.04 \mathrm{ab}$ & $0.00 \mathrm{~ns}$ & $4.83 \mathrm{ab}$ & $0.10 \mathrm{a}$ & $0.02 \mathrm{ab}$ \\
\hline \multirow[t]{2}{*}{ AgNP30L } & $21.58 \pm$ & $21.87 \pm$ & $1.13 \pm$ & $19.40 \pm$ & $40.97 \pm$ & $3.43 \pm$ & $0.33 \pm$ & $0.08 \pm$ & $173.58 \pm$ & $11.23 \pm$ & $2.33 \pm$ \\
\hline & $1.21 \mathrm{~b}$ & $0.85 \mathrm{abc}$ & $0.01 \mathrm{ab}$ & $0.85 \mathrm{~ns}$ & $0.74 \mathrm{ab}$ & $0.06 \mathrm{ab}$ & $0.01 \mathrm{ab}$ & $0.00 \mathrm{~ns}$ & $3.70 \mathrm{ab}$ & $0.03 \mathrm{abc}$ & $0.04 \mathrm{ab}$ \\
\hline \multirow[t]{2}{*}{ AgNP30M } & $21.82 \pm$ & $21.15 \pm$ & $1.12 \pm$ & $18.90 \pm$ & $39.57 \pm$ & $3.33 \pm$ & $0.33 \pm$ & $0.08 \pm$ & $207.31 \pm$ & $12.60 \pm$ & $2.59 \pm$ \\
\hline & $1.19 \mathrm{~b}$ & $0.79 \mathrm{abc}$ & $0.03 \mathrm{ab}$ & $1.13 \mathrm{~ns}$ & $1.31 \mathrm{abc}$ & $0.09 \mathrm{abc}$ & $0.04 \mathrm{ab}$ & $0.01 \mathrm{~ns}$ & $16.11 \mathrm{a}$ & $1.42 \mathrm{ab}$ & $0.23 \mathrm{ab}$ \\
\hline \multirow[t]{2}{*}{$\mathrm{AgNP} 30 \mathrm{H}$} & $20.46 \pm$ & $20.51 \pm$ & $1.14 \pm$ & $18.02 \pm$ & $35.03 \pm$ & $3.00 \pm$ & $0.36 \pm$ & $0.07 \pm$ & $177.20 \pm$ & $13.30 \pm$ & $2.65 \pm$ \\
\hline & $0.72 b c$ & $0.56 \mathrm{abc}$ & $0.01 \mathrm{ab}$ & $0.64 \mathrm{~ns}$ & $0.77 \mathrm{~d}$ & $0.05 \mathrm{~d}$ & $0.06 \mathrm{ab}$ & $0.01 \mathrm{~ns}$ & $9.18 \mathrm{ab}$ & $0.95 \mathrm{ab}$ & $0.02 \mathrm{ab}$ \\
\hline \multirow[t]{2}{*}{ AgNP50L } & $18.9 \pm$ & $20.12 \pm$ & $1.11 \pm$ & $18.12 \pm$ & $39.08 \pm$ & $3.29 \pm$ & $0.31 \pm$ & $0.08 \pm$ & $184.03 \pm$ & $12.37 \pm$ & $2.84 \pm$ \\
\hline & $0.82 b c$ & $0.18 b c$ & $0.01 \mathrm{ab}$ & $0.41 \mathrm{~ns}$ & $0.78 \mathrm{abc}$ & $0.05 b c$ & $0.01 \mathrm{ab}$ & $0.00 \mathrm{~ns}$ & $11.95 \mathrm{ab}$ & $0.63 \mathrm{ab}$ & $0.22 \mathrm{a}$ \\
\hline \multirow[t]{2}{*}{ AgNP50M } & $19.4 \pm$ & $21.44 \pm$ & $1.08 \pm$ & $19.92 \pm$ & $37.16 \pm$ & $3.17 \pm$ & $0.41 \pm$ & $0.08 \pm$ & $194.02 \pm$ & $11.23 \pm$ & $2.55 \pm$ \\
\hline & $0.76 b c$ & $0.61 \mathrm{abc}$ & $0.01 \mathrm{~b}$ & $0.78 \mathrm{~ns}$ & $0.10 \mathrm{~cd}$ & $0.01 \mathrm{~cd}$ & $0.03 \mathrm{ab}$ & $0.01 \mathrm{~ns}$ & 7.98ab & $0.75 \mathrm{abc}$ & $0.14 a b$ \\
\hline \multirow[t]{2}{*}{ AgNP50H } & $18.46 \pm$ & $21.29 \pm$ & $1.13 \pm$ & $19.05 \pm$ & $38.58 \pm$ & $3.27 \pm$ & $0.38 \pm$ & $0.08 \pm$ & $185.33 \pm$ & $12.70 \pm$ & $2.58 \pm$ \\
\hline & $0.15 b c$ & $0.55 \mathrm{abc}$ & $0.05 \mathrm{ab}$ & $1.34 \mathrm{~ns}$ & $0.22 \mathrm{bc}$ & $0.01 b c$ & $0.04 \mathrm{ab}$ & $0.00 \mathrm{~ns}$ & $8.61 \mathrm{ab}$ & $1.76 \mathrm{ab}$ & $0.29 \mathrm{ab}$ \\
\hline \multirow[t]{2}{*}{ AgNP70L } & $18.96 \pm$ & $20.48 \pm$ & $1.08 \pm$ & $19.02 \pm$ & $37.74 \pm$ & $3.21 \pm$ & $0.35 \pm$ & $0.07 \pm$ & $202.44 \pm$ & $9.90 \pm$ & $1.99 \pm$ \\
\hline & $0.85 b c$ & $1.28 \mathrm{abc}$ & $0.04 b$ & $0.60 \mathrm{~ns}$ & $0.51 b c$ & $0.04 b c$ & $0.01 \mathrm{ab}$ & $0.01 \mathrm{~ns}$ & $10.83 a$ & $0.21 b c$ & $0.11 \mathrm{ab}$ \\
\hline \multirow[t]{2}{*}{ AgNP70M } & $17.40 \pm$ & $19.10 \pm$ & $0.98 \pm$ & $19.43 \pm$ & $38.87 \pm$ & $3.24 \pm$ & $0.27 \pm$ & $0.07 \pm$ & $192.48 \pm$ & $8.40 \pm$ & $2.03 \pm$ \\
\hline & $0.55 \mathrm{bc}$ & $0.78 \mathrm{c}$ & $0.02 b$ & $0.81 \mathrm{~ns}$ & $0.74 \mathrm{abc}$ & $0.07 b c$ & $0.01 \mathrm{~b}$ & $0.01 \mathrm{~ns}$ & $9.98 \mathrm{ab}$ & $0.49 \mathrm{c}$ & $0.06 a b$ \\
\hline \multirow[t]{2}{*}{$\mathrm{AgNP70H}$} & $21.05 \pm$ & $21.78 \pm$ & $1.15 \pm$ & $18.97 \pm$ & $38.69 \pm$ & $3.26 \pm$ & $0.39 \pm$ & $0.07 \pm$ & $176.86 \pm$ & $14.33 \pm$ & $2.41 \pm$ \\
\hline & $0.25 b c$ & $0.29 \mathrm{abc}$ & $0.03 \mathrm{ab}$ & $0.57 \mathrm{~ns}$ & $0.12 b c$ & $0.01 b c$ & $0.02 \mathrm{ab}$ & $0.01 \mathrm{~ns}$ & $8.65 \mathrm{ab}$ & $1.46 \mathrm{a}$ & $0.27 \mathrm{ab}$ \\
\hline \multirow[t]{2}{*}{$\mathrm{AgNO}_{3} \mathrm{~L}$} & $19.64 \pm$ & $23.09 \pm$ & $1.12 \pm$ & $20.75 \pm$ & $38.90 \pm$ & $3.29 \pm$ & $0.40 \pm$ & $0.08 \pm$ & $166.65 \pm$ & $13.20 \pm$ & $2.13 \pm$ \\
\hline & $1.72 b c$ & $0.34 \mathrm{ab}$ & $0.04 \mathrm{ab}$ & $0.97 \mathrm{~ns}$ & $0.32 \mathrm{abc}$ & $0.02 b c$ & $0.01 \mathrm{ab}$ & $0.00 \mathrm{~ns}$ & $9.06 \mathrm{ab}$ & $0.79 \mathrm{ab}$ & $0.19 \mathrm{ab}$ \\
\hline \multirow[t]{2}{*}{$\mathrm{AgNO}_{3} \mathrm{M}$} & $19.85 \pm$ & $23.64 \pm$ & $1.14 \pm$ & $20.92 \pm$ & $38.18 \pm$ & $3.24 \pm$ & $0.42 \pm$ & $0.08 \pm$ & $152.29 \pm$ & $13.40 \pm$ & $2.19 \pm$ \\
\hline & $0.50 \mathrm{bc}$ & $0.12 \mathrm{a}$ & $0.07 \mathrm{ab}$ & $1.32 \mathrm{~ns}$ & $0.38 b c$ & $0.02 b c$ & $0.02 \mathrm{a}$ & $0.00 \mathrm{~ns}$ & $10.28 b$ & $0.42 \mathrm{ab}$ & $0.05 \mathrm{ab}$ \\
\hline \multirow[t]{2}{*}{$\mathrm{AgNO}_{3} \mathrm{H}$} & $16.83 \pm$ & $22.27 \pm$ & $1.11 \pm$ & $20.23 \pm$ & $34.83 \pm$ & $3.03 \pm$ & $0.34 \pm$ & $0.09 \pm$ & $171.27 \pm$ & $10.43 \pm$ & $1.87 \pm$ \\
\hline & $1.31 \mathrm{c}$ & $0.73 \mathrm{abc}$ & $0.04 \mathrm{ab}$ & $1.29 \mathrm{~ns}$ & $0.63 \mathrm{~d}$ & $0.07 \mathrm{~d}$ & $0.01 \mathrm{ab}$ & $0.00 \mathrm{~ns}$ & $3.23 \mathrm{ab}$ & $0.32 \mathrm{abc}$ & $0.02 \mathrm{~b}$ \\
\hline
\end{tabular}




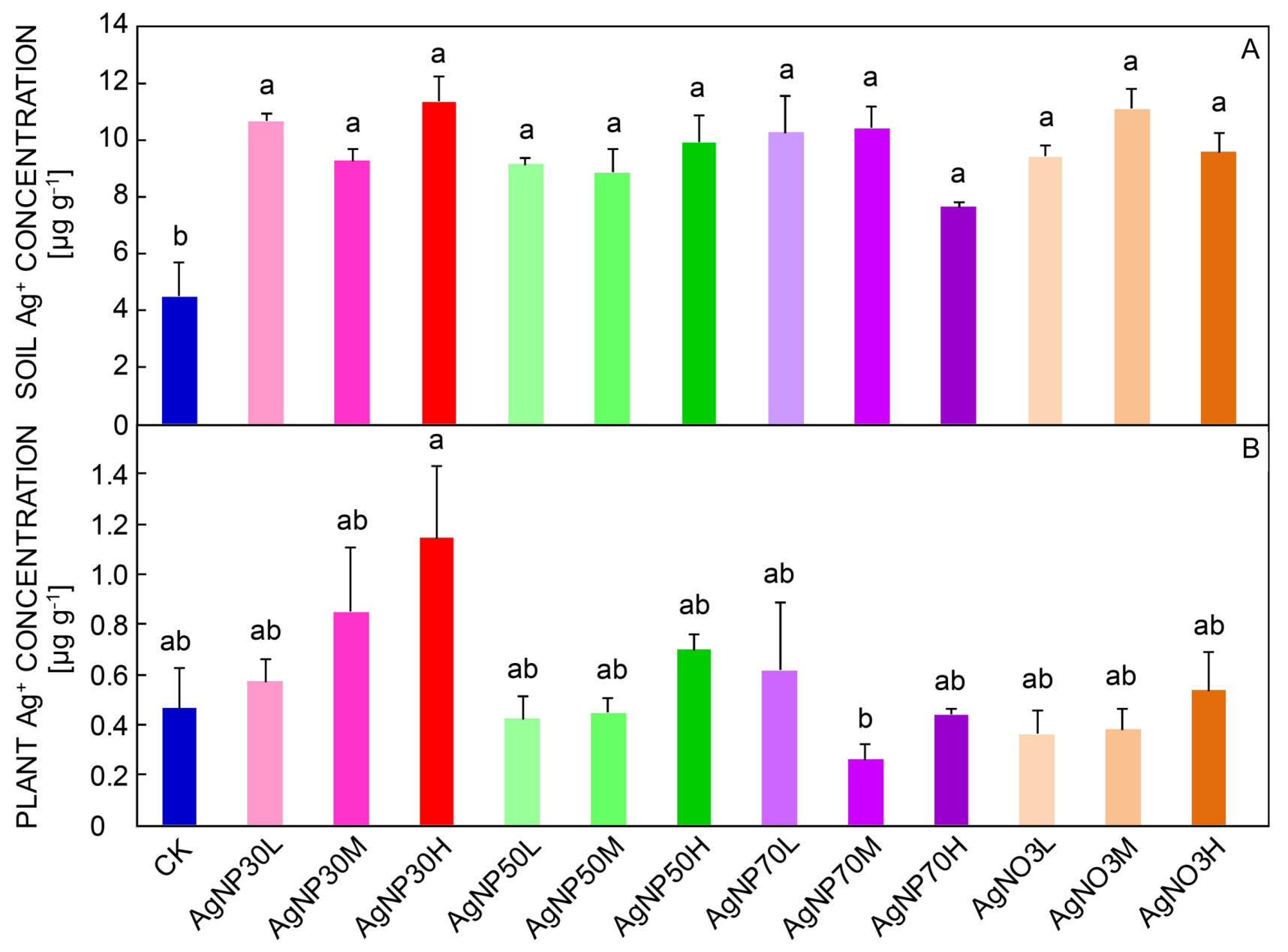

Fig. 1. Differences in Ag content in soil and plants per gramme of dry mass under silver nanoparticles (AgNPs) with different particle sizes. Means \pm SEs, $n=3$, different lowercase letters indicate significant differences $(P<0.05)$ determined by analysis of variance followed by the Student-Newman-Keuls test for multiple comparisons. Abbreviations have the same meanings as described in Table 1.

It was further observed that leaf $\mathrm{Chl}$ and $\mathrm{N}$ content decreased more under high concentration of $\mathrm{AgNO}_{3}$ than under high concentration AgNPs with sizes of 50 and $70 \mathrm{~nm}$ (Table 1). SLA was more reduced under moderate concentration of $\mathrm{AgNO}_{3}$ compared to that under moderate concentration of AgNPs with size $30 \mathrm{~nm}$. Similarly, leaf length, single leaf fresh mass, and whole shoot fresh mass were less reduced under moderate concentration of AgNPs with size of $70 \mathrm{~nm}$ than under moderate concentration of $\mathrm{AgNO}_{3}$. No significant differences were observed for all measured traits of wheat between $\mathrm{AgNPs}$ and $\mathrm{AgNO}_{3}$ under low concentration (Table 1).

Leaf $\mathrm{Chl}$ and $\mathrm{N}$ content decreased with the increasing concentration of AgNPs with size of $30 \mathrm{~nm}$ and with increasing concentrations of $\mathrm{AgNO}_{3}$ (Table 1). Leaf Chl and $\mathrm{N}$ content decreased more under high concentration of AgNPs with size $30 \mathrm{~nm}$ compared to those under high concentration of AgNPs with size of $50 \mathrm{~nm}$ and $70 \mathrm{~nm}$. Shoot fresh mass was more decreased under low and moderate concentrations of AgNPs with size of $70 \mathrm{~nm}$ when compared to that under high concentration of AgNPs with the same size (Table 1). No significant difference was observed for all measured traits of wheat among different concentrations of AgNPs with size of $50 \mathrm{~nm}(P>0.05$; Table 1).

Similarly, aboveground fresh mass was more reduced under moderate concentration of AgNPs with size of $70 \mathrm{~nm}$ compared to that under moderate concentration of AgNPs and size of $30 \mathrm{~nm}$. No significant difference was observed among the different particle sizes of AgNPs under low concentration $(P>0.05$; Table 1$)$.

Further, it was observed that soil Ag content under AgNPs and $\mathrm{AgNO}_{3}$ treatments was significantly higher when compared to control treatment (Fig. 1A). Similarly, plant Ag content under high concentration of AgNPs with size of $70 \mathrm{~nm}$ was significantly higher than that under high concentration of AgNPs with size of $30 \mathrm{~nm}$ (Fig. 1B).

No significant correlations were observed between plant Ag content and functional traits of wheat (Table 2). However, soil Ag content was negatively correlated with plant height, leaf width, and leaf $\mathrm{Chl}$ and $\mathrm{N}$ content (Table 2). 
Table 2. A relationship between the functional traits of wheat and $\mathrm{Ag}$ concentrations in soil (AgS) and plant (AgP). $P$-values equal to or less than 0.05 are shown in bold. Abbreviations have the same meanings as described in Table 1.

\begin{tabular}{lllllllllllll}
\hline & & PH & LL & LW & LSI & LCC & LNC & SLFM & SLDM & SLA & AFM & ADM \\
\hline AgS & $\mathrm{r}$ & -0.55 & -0.20 & -0.38 & 0.11 & -0.32 & -0.34 & -0.20 & -0.28 & -0.02 & -0.29 & -0.22 \\
& $P$ & $<\mathbf{0 . 0 0 1}$ & 0.2272 & $\mathbf{0 . 0 1 7 1}$ & 0.4907 & $\mathbf{0 . 0 4 4 2}$ & $\mathbf{0 . 0 3 5 1}$ & 0.2314 & 0.0883 & 0.8893 & 0.0699 & 0.1705 \\
$\mathrm{AgP}$ & $\mathrm{r}$ & 0.13 & -0.18 & 0.15 & -0.29 & -0.26 & -0.27 & -0.13 & -0.24 & 0.22 & 0.10 & 0.11 \\
& $P$ & 0.4443 & 0.2694 & 0.3482 & 0.0732 & 0.1069 & 0.0989 & 0.4230 & 0.1435 & 0.1720 & 0.5463 & 0.4964 \\
\hline
\end{tabular}

\section{Discussion}

Previous results showed that AgNPs can reduce the growth and development of many plant species (Lee et al. 2012, Yin et al. 2012, Zuverza-Mena et al. 2016, Wang et al. 2018a). In this study, it was observed that AgNPs, with all concentrations and particle sizes, significantly reduced the plant height of wheat. In addition, some treatments of AgNPs significantly reduced leaf length, leaf width, and leaf Chl and $\mathrm{N}$ content. Plant height and leaf functional traits play a critical role in the competitive ability and tolerance to environmental conditions (Gross et al. 2007, Thomson et al. 2011). Thus, the decrease in height and some leaf functional traits of wheat affected by AgNPs might suppress the competitive ability for resource acquisition, particularly sunlight. Thus AgNPs may be the ecological factor impacting the growth and development of plant species (Liu et al. 2010a, Meng et al. 2014).

Although the mechanisms of toxic effects of AgNPs have not been clearly elucidated, it is generally believed that the primary mechanisms of AgNPs toxicity is related to $\mathrm{Ag}$ ions released from AgNPs (Gubbins et al. 2011, Zhao and Wang 2012a, Guo et al. 2017, Wang et al. 2017c). Previous studies have reported that Ag ions highly accumulate in plant roots (Vannini et al. 2014, ZuverzaMena et al. 2016). In addition, it has been observed that AgNPs and $\mathrm{AgNO}_{3}$ significantly increase soil Ag content. The correlation analysis indicated that plant height, leaf width, and leaf $\mathrm{Chl}$ and $\mathrm{N}$ content of wheat were negatively affected by soil Ag content. Meanwhile, high $\mathrm{AgNO}_{3}$ concentration decreased leaf $\mathrm{Chl}$ and $\mathrm{N}$ content of wheat leaves more than high concentration of AgNPs with sizes of 50 and $70 \mathrm{~nm}$. Moreover, moderate $\mathrm{AgNO}_{3}$ concentration decreased SLA of wheat more than moderate concentration of AgNPs with size of $30 \mathrm{~nm}$. Thus, it was confirmed that Ag ions might be highly toxic to wheat plant. These results were in agreement with previous studies, which confirmed stronger toxic effects of Ag ions compared to AgNPs (Barbasz et al. 2016, Wang et al. 2017c). Reversed differences in toxic effects between $\mathrm{AgNO}_{3}$ and AgNPs treatments were also observed in this study. In particular, moderate concentration of AgNPs with size of $70 \mathrm{~nm}$ reduced leaf length, single leaf fresh mass, and whole shoot fresh mass of wheat more than AgNPs at the same concentration. The result was consistent with previous studies which confirm stronger toxic effects of AgNPs compared to Ag ions (Yin et al. 2011, 2012, Lee et al. 2012, Krajcarová et al. 2017). Hence, the toxicity of AgNPs cannot be attributed to Ag ions alone, it is highly likely that AgNPs itself has toxic properties (Lubick 2008, Yin et al. 2011, 2012, Jiang et al. 2012, Geisler-Lee et al. 2013). Further, lower accumulation of Ag ions was observed in treatments with AgNPs compared to $\mathrm{AgNO}_{3}$ (Cvjetko et al. 2017, Krajcarová et al. 2017). This phenomenon may be attributed to the mechanisms changing their ability to be absorb by plant roots. Ag ions can form complexes by binding to ligands (such as chloride, phosphate, and/or sulfide) (Xiu et al. 2011, Reinsch et al. 2012, Yang et al. 2014). In addition, Ag ions can be absorbed by colloids and/or humic acid in the soil (Wie et al. 2012, Yang et al. 2014). Further, AgNPs can be converted to Ag ions and then rapidly transformed to AgNPs in the soil subsystem or under sunlight conditions (Glover et al. 2011).

The result of this study showed that leaf $\mathrm{Chl}$ and $\mathrm{N}$ content of wheat were decreased with increasing concentration of AgNPs with size of $30 \mathrm{~nm}$. Previous studies also demonstrated that the toxic effects of AgNPs are dose-dependent, and higher concentrations usually lead to higher toxicity (Lee et al. 2012, Zuverza-Mena et al. 2016, Sheng et al. 2017, Wang et al. 2017c, 2018a). This can be attributed to the fact that AgNPs at higher concentration can release more Ag ions (Gubbins et al. 2011, Zhao and Wang, 2012a, Guo et al. 2017) and/or initiate higher ROS production (Lee et al. 2012, Zuverza-Mena et al. 2016, Cvjetko et al. 2017). However, some studies have shown positive response of some plant species to AgNPs (Sharma et al. 2012, Jasim et al. 2017). The plant growth promoting effects of AgNPs may be attributed to its effects on aminocyclopropane-1-carboxylic acid (ACC) content and production of phytohormones (Syu et al. 2014). It was also observed that low and moderate concentrations of AgNPs with size of $70 \mathrm{~nm}$ exhibit higher positive effects on wheat shoot fresh mass compared to high concentration of AgNPs. This finding may be ascribed to the fact that low and moderate concentrations of AgNPs can address hormesis effects on plant species, and thus promoting their growth (Duke et al. 2006, Jasim et al. 2017).

Further, the toxic effects of AgNPs were generally increased with decreasing particle size (Matzke et al. 2014, McGillicuddy et al. 2017). In this study, it was observed that AgNPs with smaller particle size (high concentration of AgNPs with size of $30 \mathrm{~nm}$ ) exerted higher toxicity on leaf $\mathrm{Chl}$ and $\mathrm{N}$ content than AgNPs with sizes of 50 and $70 \mathrm{~nm}$ at the same concentration). The possible reason was that smaller particle size of AgNPs would upsurge the effective surface areas and dispersity which are related to toxicity (Yuan et al. 2013, McGillicuddy et al. 2017). Another explanation may be that smaller 
particles of AgNPs can release more Ag ions than larger particles (Wang et al. 2013, Yuan et al. 2013). The result of this study also showed that plant Ag concentration under AgNPs with size of $70 \mathrm{~nm}$ was significantly higher than that under AgNPs with size of $30 \mathrm{~nm}$. This may be further attributed to the fact that AgNPs of smaller particle size of can induce more ROS, resulting in higher corresponding toxicity (Choi and $\mathrm{Hu}$ 2008, Ma et al. 2012). However, previous studies on size-dependent effects of AgNPs obtained varied results. In particular, some studies reported contrasting results that AgNPs with larger particle size were more toxic than those with smaller particle size (Contreras et al. 2014, Zhai et al. 2016, Batista et al. 2017, Wang et al. 2018a). This was in agreement with the result of this study showing that AgNPs with larger particle size (moderate concentration of AgNPs with size of $70 \mathrm{~nm}$ ) exhibited stronger toxicity on wheat shoot fresh mass than AgNPs with smaller particle size at the same concentration (a moderate concentration of AgNPs with size of $30 \mathrm{~nm}$ ). Nanoparticles with a larger particle size can increase cell wall pore size, which in turn allows the plant roots to absorb a higher amount of substances (Wild and Jones, 2009, Liu et al. 2010b). Further, AgNPs with larger particle size can be accumulated for longer duration inside the plant body than those with smaller particle size (Contreras et al. 2014) due their less aggregation and higher stability (Zhao and Wang 2012b, Gomes et al. 2013, Batista et al. 2017). Thus, AgNPs with smaller particle size may not always exhibit a stronger toxicity on the functional traits than that with larger particle size.

In conclusion, the results of this study showed that AgNPs exhibited significant negative effects on the functional traits of wheat, but these effects varied with the functional traits, particle size, and AgNPs concentration. It can be ascertained that extended application of AgNPs to soil samples may result into a change of speciation of AgNPs and to an altered bioavailability (Schlich et al. 2017). Thus, more experimental factors will be incorporated in our future research to achieve more precise information about the toxic effects of AgNPs on the growth and development of wheat.

\section{References}

Barbasz, A., Kreczmer, B., Oćwieja, M.: Effects of exposure of callus cells of two wheat varieties to silver nanoparticles and silver salt $\left(\mathrm{AgNO}_{3}\right)$. - Acta Physiol. Plant. 38: 76, 2016.

Batista, D., Pascoal, C., Cássio, F.: How do physicochemical properties influence the toxicity of silver nanoparticles on freshwater decomposers of plant litter in streams? - Ecotox. Environ. Safety 140: 148-155, 2017.

Choi, O., Hu, Z.Q.: Size dependent and reactive oxygen species related nanosilver toxicity to nitrifying bacteria. - Environ. Sci. Technol. 42: 4583-4588, 2008.

Contreras, E.Q., Puppala, H.L., Escalera, G., Zhong, W.W., Colvin, V.L.: Size-dependent impacts of silver nanoparticles on the lifespan, fertility, growth, and locomotion of Caenorhabditis elegans. - Environ. Toxicol. Chem. 33: 27162723, 2014.

Cvjetko, P., Milošić, A., Domijan, A.-M., Vrček, I.V., Tolić, S., Stefanić, P.P., Letofsky-Papst, I., Tkalec, M., Balen,
B.: Toxicity of silver ions and differently coated silver nanoparticles in Allium cepa roots. - Ecotox. Environ. Safety 137: 18-28, 2017.

Duke, S.O., Cedergreen, N., Velini, E.D., Belz, R.G.: Hormesis: is it an important factor in herbicide use and allelopathy? Outlooks Pest Manage. 17: 29-33, 2006.

Farkas, J., Christian, P., Gallego-Urrea, J.A., Roos, N., Hassellov, M., Tollefsen, K.E., Thomas, K.V.: Uptake and effects of manufactured silver nanoparticles in rainbow trout (Oncorhynchus mykiss) gill cells. - Aquat. Toxicol. 101: 117125,2011

Geisler-Lee, J., Wang, Q., Yao, Y., Zhang, W., Geisler, M., Li, K.G., Huang, Y., Chen, Y.S., Kolmakov, A., Ma X.M.: Phytotoxicity, accumulation and transport of silver nanoparticles by Arabidopsis thaliana. - Nanotoxicology 7: 323-337, 2013.

Glover, R.D., Miler, J.M., Hutchison, J.E.: Generation of metal nanoparticles from silver and copper objects: nanoparticle dynamics on surfaces and potential sources of nanoparticles in the environment. - ACS Nano 5: 8950-8957, 2011.

Gomes, S.I., Soares, A.M., Scott-Fordsmand, J.J., Amorim, M.J.: Mechanisms of response to silver nanoparticles on Enchytraeus albidus (Oligochaeta): survival, reproduction and gene expression profile. - J. Hazard. Mater. 254-255: 336344,2013

Gross, N., Suding, K.N., Lavorel, S., Roumet, C.: Complementarity as a mechanism of coexistence between functional groups of grasses. - J. Ecol. 95: 1296-1305, 2007.

Gubbins, E.J., Batty, L.C., Lead, J.R.: Phytotoxicity of silver nanoparticles to Lemna minor L. - Environ. Pollut. 159: 15511559, 2011.

Guo, Z., Chen, G.Q., Zeng, G.M., Yan, M., Huang, Z.Z., Jiang, L.H., Peng, C., Wang, J.J., Xiao, Z.H.: Are silver nanoparticles always toxic in the presence of environmental anions? Chemosphere 171: 318-323, 2017.

Hang, Z.H., Wu, H.P.: Zhenjiang Yearbook: Overview of Zhenjiang. - In: Ye, Z.G., Yang, Z.H., Pan, Y., Zhao, Y.L. (ed.): Zhenjiang Yearbook, the first edition. Vol.26. Pp. 30-31. Publishing House of Local Records, Beijing 2017.

Huang, Y.W., Wu, C.H., Aronstam, R.S.: Toxicity of transition metal oxide nanoparticles: recent insights from in vitro studies. - Materials 3: 4842-4859, 2010.

Jasim, B., Thomas, R., Mathew, J., Radhakrishnan, E.K.: Plant growth and diosgenin enhancement effect of silver nanoparticles in fenugreek (Trigonella foenum-graecum L.). - Saudi Pharm. J. 25: 443-447, 2017.

Jeong, N., Moon, J.K., Kim, H.S., Kim, C.G., Jeong, S.C.: Fine genetic mapping of the genomic region controlling leaflet shape and number of seeds per pod in the soybean. - Theor. appl. Genet. 122: 865-874, 2011.

Jiang, H.S., Li, M., Chang, F.Y., Li, W., Yin, L.Y.: Physiological analysis of silver nanoparticles and $\mathrm{AgNO}_{3}$ toxicity to Spirodela polyrhiza. - Environ. Toxicol. Chem. 31: 18801886, 2012.

Jiang, K., Wu, B.D., Wang, C.Y., Ran, Q.: Ecotoxicological effects of metals with different concentrations and types on the morphological and physiological performance of wheat. Ecotox. Environ. Safety 167: 345-353, 2019.

Kardel, F., Wuyts, K., Babanezhad, M., Vitharana, U.W.A., Wuytack, T., Potters, G., Samson, R.: Assessing urban habitat quality based on specific leaf area and stomatal characteristics of Plantago lanceolata L. - Environ. Pollut. 158: 788-794, 2010.

Kim, E., Kim, S.H., Kim, H.C., Lee, S.G., Lee, S.G., Jeong, S.W.: Growth inhibition of aquatic plant caused by silver and titanium oxide nanoparticles. - Toxicol. Environ. Health Sci. 
3: 1-6, 2011.

Kim, M.J., Kim, S.S.: Utilisation of immature wheat flour as an alternative flour with antioxidant activity and consumer perception on its baked product. - Food Chem. 232: 237-244, 2017.

Krajcarová, L., Novotný, K., Kummerová, M., Dubová, J., Gloser, V., Kaiser, J.: Mapping of the spatial distribution of silver nanoparticles in root tissues of Vicia faba by laserinduced breakdown spectroscopy (LIBS). - Talanta 173: 2835, 2017.

Lee, W.M., Kwak, J.I., An, Y.J.: Effect of silver nanoparticles in crop plants Phaseolus radiatus and Sorghum bicolor: media effect on phytotoxicity. - Chemosphere 86: 491-499, 2012.

Li, C.C., Dang, F., Li, M., Zhu, M., Zhong, H., Hintelmann, H., Zhou, D.M.: Effects of exposure pathways on the accumulation and phytotoxicity of silver nanoparticles in soybean and rice. Nanotoxicology 11: 699-709, 2017.

Li, J.M., Du, L.S., Guan, W.B., Yu, F.H., Van Kleunen, M.: Latitudinal and longitudinal clines of phenotypic plasticity in the invasive herb Solidago canadensis in China. - Oecologia 182: 755-764, 2016.

Liu, F.D., Yang, W.J., Wang, Z.S., Xu, Z., Liu, H., Zhang, M., Liu, Y.H., An, S.Q., Sun, S.C.: Plant size effects on the relationships among specific leaf area, leaf nutrient content, and photosynthetic capacity in tropical woody species. - Acta oecol. 36: 149-159, 2010.

Liu, Q.L., Zhao, Y.Y., Wan, Y.L., Zheng, J.P., Zhang, X.J., Wang, C.R., Fang, X.H., Lin, J.X.: Study of the inhibitory effect of water-soluble fullerenes on plant growth at the cellular level. - Acs. Nano 4: 5743-5748, 2010.

Lubick, N.: Nanosilver toxicity: ions, nanoparticles or both? Environ. Sci. Technol. 42: 8617, 2008.

Ma, R., Levard, C., Marinakos, S.M., Cheng, Y., Liu, J., Michel, F.M., BrownJr, G.E., Lowry, G.V.: Size-controlled dissolution of organic-coated silver nanoparticles. - Environ. Sci. Technol. 46: 752-759, 2012.

Matzke, M., Jurkschat, K., Backhaus, T.: Toxicity of differently sized and coated silver nanoparticles to the bacterium Pseudomonas putida: risks for the aquatic environment? Ecotoxicology 23: 818-829, 2014.

McGee, C.F., Storey, S., Clipson, N., Doyle, E.: Soil microbial community responses to contamination with silver, aluminium oxide and silicon dioxide nanoparticles. - Ecotoxicology 26: 449-458, 2017.

McGillicuddy, E., Murray, I., Kavanagh, S., Morrison, L., Fogarty, A., Cormican, M., Dockery, P., Prendergast, M., Rowan, N., Morris, D.: Silver nanoparticles in the environment: Sources, detection and ecotoxicology. - Sci. total Environ. 575: 231246, 2017.

Meng, F.Q., Cao, R., Yang, D.M., Niklas, K.J., Sun, S.C.: Tradeoffs between light interception and leaf water shedding: a comparison of shade- and sun-adapted species in a subtropical rainforest. - Oecologia 174: 13-22, 2014.

Ng, C.T., Li, J.J., Bay, B.H., Yung, L.Y.L.: Current studies into the genotoxic effects of nanomaterials. - J. Nucl. Acids 2010: $947859,2010$.

Nowack, B., Bucheli, T.D.: Occurrence, behavior and effects of nanoparticles in the environment. - Environ. Pollut. 150: 5-22, 2007.

Pietsch, K.A., Ogle, K., Cornelissen, J.H.C., Cornwell, W.K., Bönisch, G., Craine, J.M., Jackson, B.G., Kattge, J., Peltzer, D.A., Penuelas, J., Reich, P.B., Wardle, D.A., Weedon, J.T., Wright, I.J., Zanne, A.E., Wirth, C.: Global relationship of wood and leaf litter decomposability: the role of functional traits within and across plant organs. - Global Ecol. Biogeogr. 23: 1046-1057, 2014.
Pourzahedi, L., Eckelman, M.J.: Environmental life cycle assessment of nanosilver-enabled bandages. - Environ. Sci. Technol. 49: 361-368, 2014.

Pulit-Prociak, J., Stokłosa, K., Banach, M.: Nanosilver products and toxicity. - Environ. Chem. Lett. 13: 59-68, 2015.

Rahmatpour, S., Shirvani, M., Mosaddeghi, M.R., Nourbakhsh, F., Bazarganipour, M.: Dose-response effects of silver nanoparticles and silver nitrate on microbial and enzyme activities in calcareous soils. - Geoderma 285: 313-322, 2017.

Reinsch, B.C., Levard, C., Li, Z., Ma, R., Wise, A., Gregory, K.B., BrownJr, G.E., Lowry, G.V.: Sulfidation of silver nanoparticles decreases Escherichia coli growth inhibition. Environ. Sci. Technol. 46: 6992-7000, 2012.

Scheepens, J.F., Frei, E.S., Stöcklin, J.: Genotypic and environmental variation in specific leaf area in a widespread alpine plant after transplantation to different altitudes. Oecologia 164: 141-150, 2010.

Schlich, K., Hoppe, M., Kraas, M., Fries, E., Hund-Rinke, K.: Ecotoxicity and fate of a silver nanomaterial in an outdoor lysimeter study. - Ecotoxicology 26: 738-751, 2017.

Sharma, P., Bhatt, D., Zaidi, M.G., Saradhi, P.P., Khanna, P.K., Arora, S.: Silver nanoparticle mediated enhancement in growth and antioxidant status of Brassica juncea. - Appl. Biochem. Biotechnol. 167: 2225-2233, 2012.

Sheng, Z.Y., Liu, Y.: Potential impacts of silver nanoparticles on bacteria in the aquatic environment. - J. Environ. Manage. 191: 290-296, 2017.

Syu, Y.Y., Hung, J.H., Chen, J.C., Chuang, H.W.: Impacts of size and shape of silver nanoparticles on Arabidopsis plant growth and gene expression. - Plant Physiol. Biochem. 83: 57-64, 2014.

Thomson, F.J., Moles, A.T., Auld, T.D., Kingsford, R.T.: Seed dispersal distance is more strongly correlated with plant height than with seed mass. - J. Ecol. 99: 1299-1307, 2011.

Vannini, C., Domingo, G., Onelli, E., De Mattia, F., Bruni, I., Marsoni, M., Bracale, M.: Phytotoxic and genotoxic effects of silver nanoparticles exposure on germinating wheat seedlings. - J. Plant Physiol. 171: 1142-1148, 2014.

Vile, D., Garnier, E., Shipley, B., Laurent, G., Navas, M.L., Roumet, C., Lavorel, S., Díaz, S., Hodgson, J.G., Lloret, F., Midgley, G.F., Poorter, H., Rutherford, M.C., Wilson, P.J., Wright, I.J.: Specific leaf area and dry matter content estimate thickness in laminar leaves. - Ann. Bot. 96: 1129-1136, 2005.

Wan, R., Mo, Y.Q., Feng, L.F., Chien, S., Tollerud, D.J., Zhang, Q.W.: DNA damage caused by metal nanoparticles: involvement of oxidative stress and activation of ATM. Chem. Res. Toxicol. 25: 1402-1411, 2012.

Wang, C.Y., Jiang, K., Wu, B.D., Zhou, J.W., Lv, Y.N.: Silver nanoparticles with different particle sizes enhance the allelopathic effects of Canada goldenrod on the seed germination and seedling development of lettuce. Ecotoxicology 27: 1116-1125, 2018a.

Wang, C.Y., Jiang, K., Liu, J., Zhou, J.W., Wu, B.D.: Moderate and heavy Solidago canadensis L. invasion are associated with decreased taxonomic diversity but increased functional diversity of plant communities in East China. - Ecol. Eng. 112: 55-64, 2018b.

Wang, C.Y., Liu, J., Xiao, H.G., Zhou, J.W.: Differences in leaf functional traits between Rhus typhina and native species. Clean-Soil Air Water 44: 1591-1597, 2016.

Wang, C.Y., Wu, B.D., Jiang, K., Zhou, J.W.: Differences in functional traits between invasive and native Amaranthus species under simulated acid deposition with a gradient of $\mathrm{pH}$ levels. - Acta oecol. 89: 32-37, 2018c.

Wang, C.Y., Wu, B.D., Jiang, K., Zhou, J.W.: Effects of different types of heavy metal pollution on functional traits of invasive 
redroot pigweed and native red amaranth. - Int. J. environ. Res. 12: 419-427, 2018d.

Wang, C.Y., Zhou, J.W., Jiang, K., Liu, J.: Differences in leaf functional traits and allelopathic effects on seed germination and growth of Lactuca sativa between red and green leaves of Rhus typhina. - S. Afr. J. Bot. 111: 17-22, $2017 \mathrm{~b}$.

Wang, C.Y., Zhou, J.W., Liu, J., Jiang, K.: Differences in functional traits between invasive and native Amaranthus species under different forms of $\mathrm{N}$ deposition. - Sci. Nat. 104: 59, 2017a.

Wang, C.Y., Zhou, J.W., Liu, J., Wang, L., Xiao, H.G.: Reproductive allocation strategy of two herbaceous invasive plants across different cover classes. - Pol. J. Environ. Stud. 26: 355-364, 2017d.

Wang, C.Y., Zhou, J.W., Liu, J., Xiao, H.G., Wang, L.: Functional traits and reproductive allocation strategy of Conyza canadensis as they vary by invasion degree along a latitude gradient. - Pol. J. Environ. Stud. 26: 1289-1297, 2017 e.

Wang, J., Koo, Y., Alexander, A., Yang, Y., Westerhof, S., Zhang, Q., Schnoor, J.L., Colvin, V.L., Braam, J., Alvarez, P.J.J.: Phytostimulation of poplars and arabidopsis exposed to silver nanoparticles and $\mathrm{Ag}^{+}$at sublethal concentrations. - Environ. Sci. Technol. 47: 5442-5449, 2013.

Wang, J., Shu, K.H., Zhang, L., Si, Y.B.: Effects of silver nanoparticles on soil microbial communities and bacterial nitrification in suburban vegetable soils. - Pedosphere 27: 482-490, 2017c.

Wang, Z., Zhang, L.: Leaf shape alters the coefficients of leaf area estimation models for Saussurea stoliczkai in central Tibet. - Photosynthetica 50: 337-342, 2012.

Wie, M.A., Oh, S.J., Kim, S.C., Kim, R.Y., Lee, S.P., Kim, W.I., Yang, J.E.: Toxicity assessment of silver ions compared to silver nanoparticles in aqueous solutions and soils using microtox bioassay. - Korean J. Soil Sci. Fert. 45: 1114-1119, 2012.

Wild, E., Jones, K.C.: Novel method for the direct visualization of in vivo nanomaterials and chemical interactions in plants. Environ. Sci. Technol. 43: 5290-5294, 2009.

Xiu, Z.M., Ma, J., Alvarez, P.J.: Differential effect of common ligands and molecular oxygen on antimicrobial activity of silver nanoparticles versus silver ions. - Environ. Sci. Technol. 45: 9003-9008, 2011.

Yang, Y., Quensen, J., Mathieu, J., Wang, Q.,Wang, J., Li, M., Tiedje, J.M., Alvarez, P.J.J.: Pyrosequencing reveals higher impact of silver nanoparticles than $\mathrm{Ag}^{+}$on the microbial community structure of activated sludge. - Water Res. 48: 317-325, 2014.

Yin, L.Y., Cheng, Y.W., Espinasse, B., Colman, B.P., Auffan, M., Wiesner, M., Rose, J., Liu, J., Bernhardt, E.S.: More than the ions: the effects of silver nanoparticles on Lolium multiflorum. - Environ. Sci. Technol. 45: 2360-2367, 2011.

Yin, L.Y., Colman, B.P., McGill, B.M., Wright, J.P., Bernhardt, E.S.: Effects of silver nanoparticle exposure on germination and early growth of eleven wetland plants. - PLoS ONE 7: e47674, 2012.

Yuan, Z.H., Li, J.W., Cui, L., Xu, B., Zhang, H.W., Yu, C.P.: Interaction of silver nanoparticles with pure nitrifying bacteria. - Chemosphere 90: 1404-1411, 2013.

Zhai, Y.J., Hunting, E.R., Wouters, M., Peijnenburg, W.J.G.M., Vijver, M.G.: Silver nanoparticles, ions, and shape governing soil microbial functional diversity: nano shapes micro. Front. Microbiol. 7: 1123, 2016.

Zhao, C.M., Wang, W.X.: Size-dependent uptake of silver nanoparticles in Daphnia magna. - Environ. Sci. Technol. 46: 11345-11351, 2012a.

Zhao, C.M., Wang, W.X.: Importance of surface coatings and soluble silver in silver nanoparticles toxicity to Daphnia magna. - Nanotoxicology 6: 361-370, 2012 b.

Zuverza-Mena, N., Armendariz, R., Peralta-Videa, J.R., GardeaTorresdey, J.L.: Effects of silver nanoparticles on radish sprouts: root growth reduction and modifications in the nutritional value. - Front. Plant Sci. 7: 90, 2016. 